\title{
Effects of Homogeneous Low Energy Electron Beam Irradiation (HLEBI) on Adhesive Force of Peeling Resistance of Laminated Sheet with Polyethylene (PE) and Austenitic 18-8 Stainless Steels
}

\author{
Chisato Kubo ${ }^{1, *}$, Masae Kanda ${ }^{2}$, Olivier Lame ${ }^{3}$, Jean-Yves Cavaille ${ }^{3}$ and Yoshitake Nishi ${ }^{1,2}$ \\ ${ }^{1}$ Graduate School of Engineering, Tokai University, Hiratsuka 259-1292, Japan \\ ${ }^{2}$ School of Engineering, Tokai University, Hiratsuka 259-1292, Japan \\ ${ }^{3}$ MATEIS, UMR CNRS-INSA Lyon, Université de Lyon, 69621 Villeurbanne France
}

\begin{abstract}
2-layer laminated sheets (PE/18-8) with Polyethylene (PE) and austenitic 18-8 stainless steels (18-8) were prepared by a new adhesion method, a double-step treatment consisting of applying low dose ( $\leqq 0.43 \mathrm{MGy}$ ) homogeneous low energy electron beam irradiation (HLEBI) prior to hot-press under $5 \mathrm{MPa}$ and $343 \mathrm{~K}$. Although the weak hot-press adhesion of the PE/18-8 was observed without HLEBI, the new adhesion raised the bonding forces as evidenced by the mean adhesive forces of peeling resistance $\left({ }^{\circ} F_{\mathrm{p}}\right)$. Based on the 3 -parameter Weibull equation, the lowest ${ }^{\circ} F_{\mathrm{p}}$ value at peeling probability $\left(P_{\mathrm{p}}\right)$ of zero $\left(F_{\mathrm{s}}\right)$ could be estimated. An increasing trend in $F_{\mathrm{s}}$ occurred by the double-step treatment applying HLEBI up to $0.30 \mathrm{MGy}$ reaching a maximum at $0.85 \mathrm{Nm}^{-1}$, improving the safety level without radiation damage. When HLEBI cut the chemical bonds in PE polymer and generated terminated atoms with dangling bonds, they probably induced the chemical bonding. Therefore, increasing adhesion force between the laminated sheets could be explained. [doi:10.2320/matertrans.MBW201509]
\end{abstract}

(Received October 13, 2015; Accepted January 6, 2016; Published February 25, 2016)

Keywords: joint, adhesion, electron beam, irradiation, polyethylene (PE), austenitic stainless steels (18-8)

\section{Introduction}

Techniques to increase the strength of metal/composite joints are highly sought after. Polyethylene (PE) exhibits high wear resistance and high strength as well as transparency. ${ }^{1)}$ Austenite stainless steel (18-8) for structural applications has been widely utilized in the aerospace, automotive and shipbuilding industries, along with various day-to-day items.

The adhesion method to prepare 2-layer laminated sheets (PE/18-8) with PE and 18-8 is important technology to be utilized for biomedical application. However no one has been probably reported in international journals. The CFRP/18-8 adhesion treated by homogeneous low energy electron beam irradiation (HLEBI) prior to hot-press has been found. ${ }^{2)}$ HLEBI improves the mist resistance and wetting of inorganic materials, ${ }^{3)}$ and increases polymer adhering to glass fibers raising impact strength in GFRP. ${ }^{4)}$

Applying surface treatment of low dose of electron beam (EB) irradiation on the order of 0.01 to $1 \mathrm{MGy}$ has been gaining momentum as a successful method to adhere polymeric materials without the use of adhesive. Polyimide/polytetrafluoroethylene (PI/PTFE) layered films have been successfully fabricated by homogeneous low energy electron beam irradiation (HLEBI), ${ }^{5)}$ while applying 0.50 MGy EB dose increased adhesive bond strength between PET films and acrylic adhesive. ${ }^{6}$ HLEBI has been found to increase adhesive mechanical properties of polymer-polymer joints for biomedical applications of PDMS (polydimethylsilozane)/PTFE, ${ }^{7)}$ PDMS/PP (polypropylene), ${ }^{8)}$ and create strong adhesion in the difficult to bond PTFE/PE (polyethylene). ${ }^{9)}$

Improvements are mainly caused by the irradiation with the formation of dangling bonds at terminated atoms in

*Graduate Student, Tokai University polymers. ${ }^{10)}$ Dangling bonds enhance surface energy, which is probably the mechanism for joining the different polymers. ${ }^{11)}$ When free electrons on PE and 18-8 surface act as bonding electrons like dangling bonds in polymer, rapid and strong adhesion of PE/18-8 by using HLEBI prior to hotpress can be expected. Therefore, the effects of HLEBI prior to hot-press lamination on the adhesive force of peeling resistance of bio-adaptable and high strength $\mathrm{PE} / 18-8$ laminated sheets of PE/18-8 have been investigated.

\section{Experimental Procedure}

\subsection{Preparation of PE/18-8 laminated sheets}

Composite sheets were constructed with $18-8(10 \mathrm{~mm} \times$ $40 \mathrm{~mm} \times 0.02 \mathrm{~mm}$, Nilaco Co., Ltd. $)$ and PE $(10 \mathrm{~mm} \times$ $40 \mathrm{~mm} \times 0.08 \mathrm{~mm}$, High-star PE 100, Star plastic Industry Inc., Japan). The glass transition temperatures $\left(T_{\mathrm{g}}\right)$ of $\mathrm{PE}$ is $183-194 \mathrm{~K}^{12)}$

\subsection{Homogeneous low energy electron beam irradiation (HLEBI)}

The PE/18-8 laminated sheets was irradiated by using an electron-curtain processor (Type CB250/15/10 mA, Energy Science Inc., Woburn, MA, Iwasaki Electric Group Co. Ltd. Tokyo). ${ }^{13-22)}$ The specimen was homogeneously irradiated with the sheet HLEBI with low energy through a titanium thin film window attached to a $240 \mathrm{~mm}$ diameter vacuum chamber. A tungsten filament in a vacuum is used to generate the electron beam at a low energy (acceleration potential, $V: \mathrm{kV})$, of $170 \mathrm{keV}$ and irradiating current density $\left(I, \mathrm{~A} / \mathrm{m}^{2}\right)$ of $0.089 \mathrm{~A} / \mathrm{m}^{2}$.

Although the sheet electron beam generation is in a vacuum, the irradiated sample has been kept under protective nitrogen at atmospheric pressure. The distance between sample and window is $35 \mathrm{~mm}$. To prevent oxidation, the samples are kept in a protective atmosphere of nitrogen gas 
with a residual concentration of oxygen below $400 \mathrm{ppm}$. The flow rate of nitrogen gas is $1.5 \mathrm{~L} / \mathrm{s}$ at $0.1 \mathrm{MPa}$ nitrogen gas pressure.

The absorbed dose is controlled by the integrated irradiation time in each of the samples. Here, absorbed dose is corrected from irradiation dose by using an FWT nylon dosimeter of RCD radiometer film (FWT-60-00: Far West Technology, Inc. 330-D South Kellogg Goleta, California 93117, USA) with an irradiation reader (FWT-92D: Far West Technology, Inc. 330-D South Kellogg Goleta, California 93117, USA). The absorbed dose corresponded to irradiation dose is $0.0432 \mathrm{MGy}$ at each irradiation, which is applied for only a short time $(0.23 \mathrm{~s})$ to avoid excessive heating of the sample; the temperature of the sample surface remains below $323 \mathrm{~K}$ just after irradiation. The sample in the aluminum plate holder $(0.15 \mathrm{~m} \times 0.15 \mathrm{~m})$ is transported on a conveyor at a speed of $9.56 \mathrm{~m} / \mathrm{min}$. The sheet HLEBI is applied intermittently. Repeated irradiations to both side surfaces of the samples are used to increase the total irradiation dose. The interval between the end of one period of irradiation and the start of the next operation is $30 \mathrm{~s}$. When the irradiation current $(I, \mathrm{~mA})$, the conveyor speed $(S, \mathrm{~m} / \mathrm{min})$ and number of irradiations $(N)$ are determined, the irradiated dosage is proportional to the yield value from the irradiation current ( $I, \mathrm{~mA})$, the conveyor speed $(S, \mathrm{~m} / \mathrm{min})$, and number of irradiations $(N)$.

Based on the density $\left(\rho: \mathrm{kg} / \mathrm{m}^{3}\right)$ and irradiation voltage at the specimen surface $(V: \mathrm{kV})$, the penetration depth $\left(D_{\mathrm{th}}: \mathrm{m}\right)$ of HLEBI is expressed by the following equation. ${ }^{23)}$

$$
D_{\text {th }}=66.7 V^{5 / 3} / \rho
$$

Specimen surface electrical potential $(V)$ was mainly reduced going through the Ti window $\left(\Delta V_{\mathrm{Ti}}\right)$ and $\mathrm{N}_{2}$ gas atmosphere $\left(\Delta V_{\mathrm{N} 2}\right)$.

$$
V=170 \mathrm{keV}-\Delta V_{\mathrm{Ti}}-\Delta V_{\mathrm{N} 2}
$$

Based on eq. (2), the dropped potential values, $\Delta V_{\mathrm{Ti}}$ and $\Delta V_{\mathrm{N} 2}$ are estimated from the acceleration potential $(170 \mathrm{keV})$, the $10 \mu \mathrm{m}$ thickness $\left(T_{\mathrm{Ti}}\right)$ of the titanium window (density: $4540 \mathrm{~kg} \mathrm{~m}^{-3}$ ), and the $35 \mathrm{~mm}$ distance between the sample and the window $\left(T_{\mathrm{N} 2}\right)$ in the $\mathrm{N}_{2}$ gas atmosphere (density: $\left.\rho_{\mathrm{N} 2}=1.13 \mathrm{~kg} \mathrm{~m}^{-3}\right)$.

$$
\begin{aligned}
V_{\mathrm{Ti}}= & \left(T_{\mathrm{Ti}} / \mathrm{D}_{\mathrm{thTi}}\right) \times 170 \mathrm{keV} \\
= & T_{\mathrm{Ti}} \rho_{\mathrm{Ti}} /\left[66.7 \times(170 \mathrm{keV})^{2 / 3}\right] \\
= & \left(10^{-5} \mathrm{~m}\right) \times\left(4540 \mathrm{~kg} \mathrm{~m}^{-3}\right) /\left[66.7 \times(170 \mathrm{keV})^{2 / 3}\right] \\
= & 22.2 \mathrm{keV} \\
\Delta V_{\mathrm{N} 2}= & \left(T_{\mathrm{N} 2} / \mathrm{D}_{\mathrm{thiN} 2}\right) \times V_{\mathrm{Ti}} \\
= & T_{\mathrm{N} 2} \rho_{\mathrm{N} 2} /\left[66.7 \times\left(V_{\mathrm{Ti}}\right)^{2 / 3}\right] \\
= & \left(35 \times 10^{-3} \mathrm{~m}\right) \times\left(1.13 \mathrm{~kg} \mathrm{~m}^{-3}\right) \\
& /\left[66.7 \times(170 \mathrm{keV})^{2 / 3}\right]
\end{aligned}
$$

Since the dropped potential values are 22.2 and $18.2 \mathrm{keV}$, the specimen surface electrical potential, $V$ is $129.6 \mathrm{keV}$ as follows.

$$
V=170 \mathrm{keV}-22.2 \mathrm{keV}-18.2 \mathrm{keV}=129.6 \mathrm{keV}
$$

Given typical density of PE is $863 \mathrm{~kg} \mathrm{~m}^{-3}$, the HLEBI depth into the PE film estimated from eq. (1) is $D_{\text {th }}=229 \mu \mathrm{m}$,

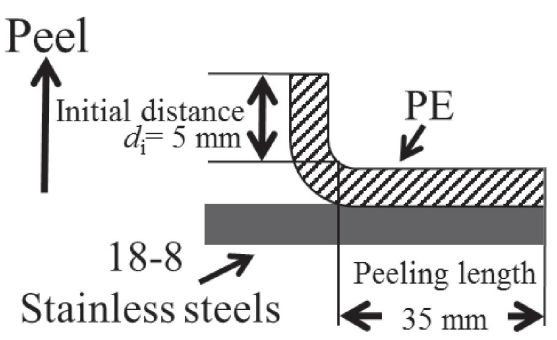

Fig. 1 Schematic diagram of $90^{\circ}$-peeling test of the $\mathrm{PE} / 18-8$ polymers laminate sheet.

more than four times larger than the PE thickness of $80 \mu \mathrm{m}$, hence the HLEBI penetrated through the entire thickness.

\section{$2.3 \quad 90^{\circ}$-peeling test}

Composite samples after hot-press under $5 \mathrm{MPa}$ at $343 \mathrm{~K}$ were prepared for the $90^{\circ}$-peeling test to evaluate the influence of HLEBI on the mean adhesive force of peeling resistance $\left({ }^{\circ} F_{\mathrm{p}}\right)$, as shown in Fig. 1 . Peeling load $\left(L_{\mathrm{p}}\right)$ vs. peeling distance $\left(d_{\mathrm{p}}\right)$ curves were obtained by using a microload tensile tester (F-S Master-1K-2N, IMADA Co. Ltd., Japan) with a strain rate of $10 \mathrm{~mm} / \mathrm{min}^{7)}$ Since the unit of the $F_{\mathrm{p}}$ was $\mathrm{N} \mathrm{m}^{-1}$, the ${ }^{\mathrm{o}} F_{\mathrm{p}}$ was used instead of the adhesive strength, whose units should be $\mathrm{N} \mathrm{m}^{-2}$. The sample condition of tensile test was as follows:

(1) The vertical length from the peeling contact point to the end of the sample was $5 \mathrm{~mm}$.

(2) The $F_{\mathrm{p}}$ was determined by using micro-load tensile tester. The ${ }^{\mathrm{o}} F_{\mathrm{p}}$ was estimated by the peeling load and experimental peeling width and length of 10 and $35 \mathrm{~mm}$, respectively. The initial distance before peeling $\left(d_{\mathrm{i}}\right)$ was defined at the start point of peeling force, which corresponds to the start point of the first relaxation. The $d_{\mathrm{i}}$ value is $\sim 1 \mathrm{~mm}$.

\subsection{Peeling probability}

The accumulated probability $(P)$ of Median Rank meth$\mathrm{od}^{24)}$ is one of convenient ways to analyze the mechanical probabilities of adhesive strength, ${ }^{25,26)}$ adhesive peeling resistance $^{7)}$ and elasticity, ${ }^{27)}$ as well as strength and impact value on fracture. ${ }^{28-34)}$ This method is useful to evaluate the effects of process, precisely. Evaluating the peeling probability $\left(P_{\mathrm{p}}\right)$ is also the convenient method of quantitative analyzing experiment values relating to peeling resistance. ${ }^{7)}$ It is expressed by the following equation.

$$
P_{\mathrm{p}}=(I-0.3) /(n+0.4)
$$

Here, $n$ and $I$ are the total number of samples $(n=11)$ and order of peeling of each sample $(0 \leqq I \leqq 11)$, respectively. When the $I$ values were 1,6 , and 11 , the $P_{\mathrm{p}}$ values were 0.06 , 0.50 and 0.94 , respectively.

\subsection{X-ray photoelectron spectrometer (XPS) measure- ments}

X-ray photoelectron spectrometer (XPS: Quantum 2000, ULVAC Co., JAPAN) ${ }^{7}$ ) was used for surface analysis of peeled 0.30 MGy HLEBI 18-8 stainless and PE. Both 18-8 stainless and PE contain elements $\mathrm{C}$ and $\mathrm{O}$. Narrow scans for the $\mathrm{C}(1 \mathrm{~s})$ and $\mathrm{O}(1 \mathrm{~s})$ signals from the $\mathrm{PE}$ and $18-8$ surfaces were detected by the XPS. 


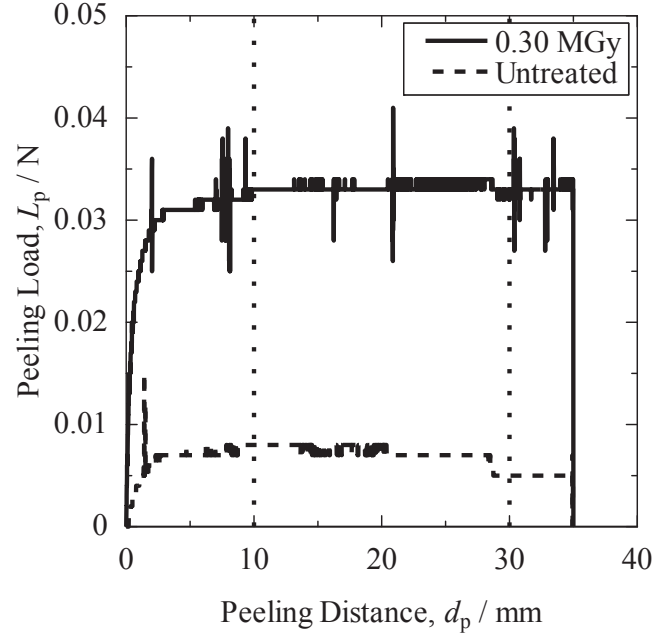

Fig. 2 Peeling load $\left(L_{\mathrm{p}}\right)$-peeling distance $\left(d_{\mathrm{p}}\right)$ curves of PE/18-8 laminated sheets before and after $0.30 \mathrm{MGy}-\mathrm{HLEBI}$ at $P_{\mathrm{p}}$ of 0.50 .

\section{Results}

\subsection{Peeling load $\left(L_{\mathrm{p}}\right)$-Peeling distance $\left(d_{\mathrm{p}}\right)$ curve}

Figure 2 shows a comparison of $L_{\mathrm{p}}(\mathrm{N})$ vs. peeling distance, $d_{\mathrm{p}}(\mathrm{mm})$ curves between HLEBI and untreated PE/ 18-8 joint at median accumulative probability of peeling force, $P_{\mathrm{p}}=0.50$. Although without HLEBI a large adhesive load of peeling resistance in the PE/18-8 could not be obtained, by applying HLEBI at $0.30 \mathrm{MGy}$ the peeling load, $L_{\mathrm{p}}$ is significantly increased $(\sim 1.9 \mathrm{~N})$ over the low value of the untreated $(\sim 0.20 \mathrm{~N})$. The $0.30 \mathrm{MGy}$-HLEBI therefore laminates the PE with the 18-8 stainless, generating the higher peeling resistance. Based on the optical scale observation, the fracture can be seen to always occur at the interface.

\subsection{Adhesive force of peeling $\left({ }^{\circ} F_{\mathrm{p}}\right)$ as a function of} accumulative probability of peeling force $\left(P_{p}\right)$

Figure 3 plots the relationships between the adhesive force of peeling resistance $\left({ }^{\circ} F_{\mathrm{p}}\right)$ and peeling probability $\left(P_{\mathrm{p}}\right)$ of the PE/18-8 laminated sheets for the untreated and HLEBItreated. Applying $0.30 \mathrm{MGy}$ HLEBI gives the highest ${ }^{\circ} F_{\mathrm{p}}$ values at low $P_{\mathrm{p}}<0.4$. Figure 4 shows the maximum ${ }^{\circ} F_{\mathrm{p}}$ for low- and median- $P_{\mathrm{p}}$ of 0.06 and 0.50 against HLEBI occurs in the $0.30 \mathrm{MGy}-\mathrm{HLEBI}$ samples at 0.9 and $3.3 \mathrm{Nm}^{-1}$, respectively. They were up to 0.9 and $3.3 \mathrm{~N} \mathrm{~m}^{-1}$ larger than 0 and $0 \mathrm{~N} \mathrm{~m}^{-1}$ before treatment. All ${ }^{\circ} F_{\mathrm{p}}$ values of PE/18-8 laminated sheets with small dose of 0.04 to $0.43 \mathrm{MGy}$ apparently exceed all corresponding values of untreated samples. Thus, adhesion of PE/18-8 laminated sheets with small dose from 0.04 to $0.43 \mathrm{MGy}-\mathrm{HLEBI}$ deems effective.

\section{Discussion}

\subsection{The statistically lowest adhesive force}

In order to obtain the statistically lowest peeling stress for safety design, the lowest ${ }^{\circ} F_{\mathrm{p}}$ value at $P_{\mathrm{p}}=0\left(F_{\mathrm{s}}\right)$ is assumed to be attained from the adaptable relationship of the 3 -parameter Weibull equation iterating to the high correlation coefficient $(F)$. The $P_{\mathrm{p}}$ depends on the risk of rupture $\left(\left[{ }^{\mathrm{o}} F_{\mathrm{p}}-F_{\mathrm{s}}\right] / F_{\mathrm{III}}\right)^{7,27,31-36)}$

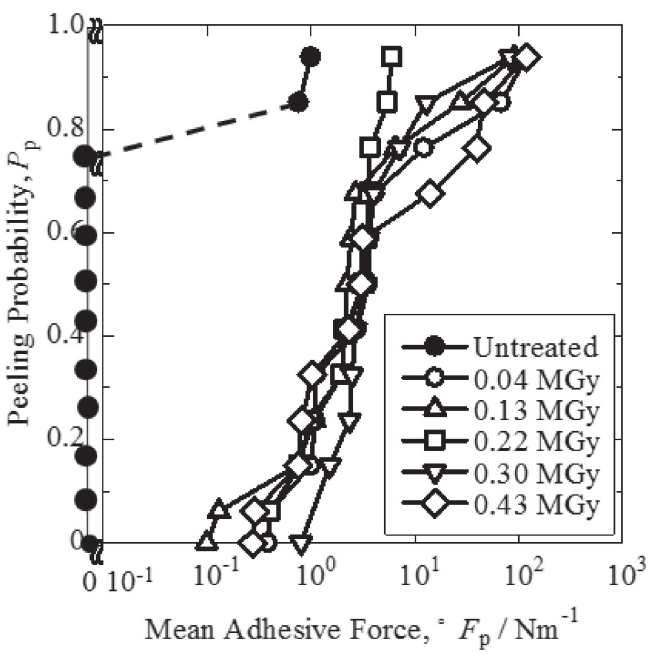

Fig. 3 Relationships between ${ }^{\circ} F_{\mathrm{p}}$ and $P_{\mathrm{p}}$ of $\mathrm{PE} / 18-8$ laminated sheets untreated and HLEBI-treated.

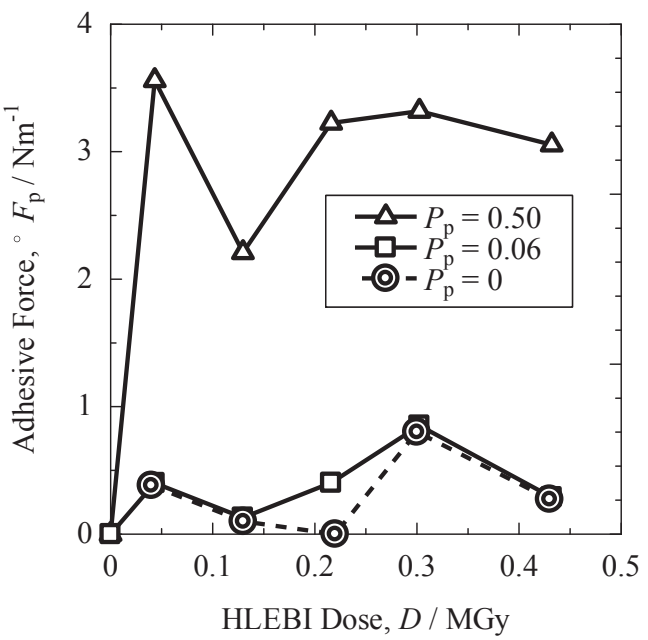

Fig. 4 Changes in experimental ${ }^{\circ} F_{\mathrm{p}}$ at each $P_{\mathrm{p}}$ of PE/18-8 laminated sheets at low-, median-, and high- $P_{\mathrm{p}}$ of $0.06,0.50$ and 0.94 against absorbed dose.

$$
P_{\mathrm{p}}=1-\exp \left[-\left(\left[^{\mathrm{o}} F_{\mathrm{p}}-F_{\mathrm{s}}\right] / F_{\mathrm{III}}\right)^{m}\right]
$$

The $F_{\text {III }}$ value is the ${ }^{\circ} F_{\mathrm{p}}$ value, when the term $\ln \left[-\ln \left(1-P_{\mathrm{p}}\right)\right]$ is zero. When $P_{\mathrm{p}}=0$, the required ${ }^{\mathrm{o}} F_{\mathrm{p}}$ value to evaluate new structural materials is defined as the $F_{\mathrm{s}}$. In predicting the $F_{\mathrm{s}}$, coefficient $(m)$ and constant $\left(F_{\mathrm{III}}\right)$ are the key parameters. Figure 5 plots the iteration to obtain the highest correlation coefficient $(F)$ with respect to the potential adhesive force of peeling ${ }^{\circ} F_{\mathrm{s}}$ value $\left({ }^{e} F_{\mathrm{s}}\right)$ estimated from the logarithmic form.

Figure 6 illustrates the linear relationships between $\ln$ $\left({ }^{\circ} F_{\mathrm{p}}-F_{\mathrm{s}}\right)$ and $\ln \left[-\ln \left(1-P_{\mathrm{p}}\right)\right]$. The values of $F_{\text {III }}$ and $m$ are determined by the least-squares best fit method. The $m$ value is estimated by the slope of the relationship when ${ }^{e} F_{\mathrm{s}}=F_{\mathrm{s}}$. The constant values of $m, F_{\mathrm{III}}$ and $F_{\mathrm{S}}$ are summarized in Table 1.

Figure 4 shows $F_{\mathrm{s}}$ is always lower than the experimental ${ }^{\circ} F_{\mathrm{p}}$ value. The HLEBI from 0.04 and 0.22 to $0.43 \mathrm{MGy}$ improves the $F_{\mathrm{S}}$ values of the PE/18-8 laminated sheets over that of the untreated. The $0.30 \mathrm{MGy}$-HLEBI apparently enhances the $F_{\mathrm{s}}$ from $0 \mathrm{Nm}^{-1}$ for the untreated to 0.8 $\mathrm{N} \mathrm{m}^{-1}$, as well as at low $P_{\mathrm{p}}$ of 0.06 (the lowest experimental 


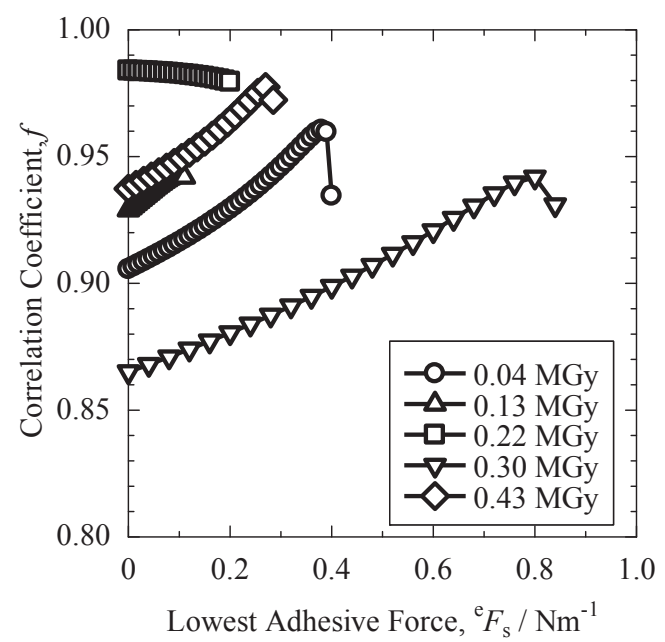

Fig. 5 Changes in correlation coefficient $(F)$ of eq. (1) against the potential ${ }^{\mathrm{o}} F_{\mathrm{s}}$ value $\left({ }^{\mathrm{e}} F_{\mathrm{s}}\right)$ for PE/18-8 laminated sheets at each absorbed dose of HLEBI.

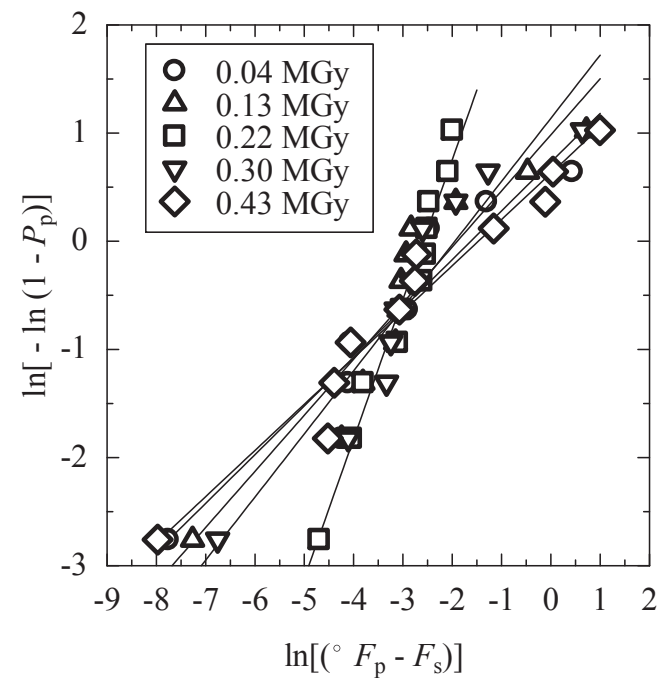

Fig. 6 Liner relationships between $\ln \left({ }^{\circ} F_{\mathrm{p}}-F_{\mathrm{s}}\right)$ and $\ln \left[-\ln \left(1-P_{\mathrm{p}}\right)\right]$ for PE/18-8 laminated sheets at each absorbed dose of HLEBI.

Table 1 Constant values of $m, F_{\mathrm{III}}$ and $F_{\mathrm{S}}$ are summarized.

\begin{tabular}{cccc}
\hline HLEBI & $m$ & $F_{\text {III }}$ & $F_{\mathrm{s}}$ \\
\hline 0.04 & 0.45 & 44.12 & 0.38 \\
0.13 & 0.51 & 31.61 & 0.1 \\
0.22 & 1.29 & 3.73 & 0 \\
0.3 & 0.58 & 29.55 & 0.8 \\
0.43 & 0.42 & 42.61 & 0.27 \\
\hline
\end{tabular}

${ }^{\mathrm{o}} F_{\mathrm{p}}$ ) from 0 for the untreated to $0.9 \mathrm{Nm}^{-1}$. Consequently, HLEBI enhances the safety level (reliability) of PE/18-8 laminated sheets. This indicates HLEBI induced adhesion can be applied to practical articles with sterilization without volatilization, when the adhesive force of peeling resistivity is less than $0.8 \mathrm{Nm}^{-1}$.

\subsection{X-ray photoelectron spectrometry (XPS) of PE surface}

Figure 7 and Figure 8 show fracture surface analysis by X-

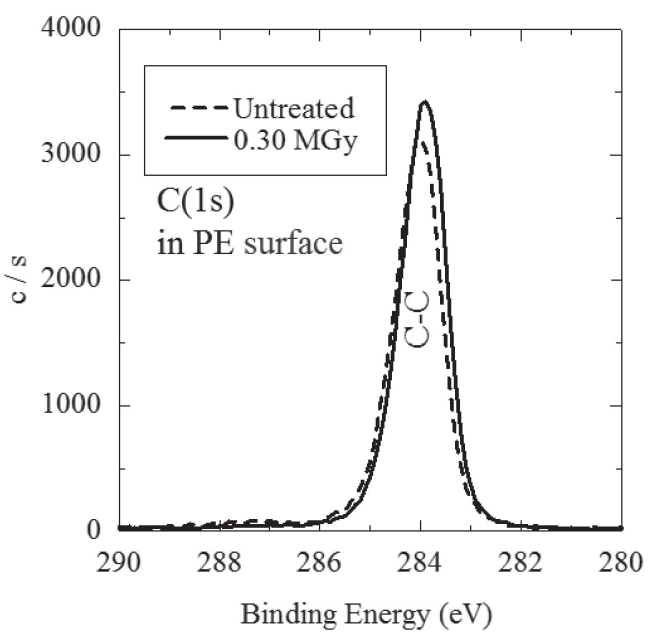

Fig. 7 Carbon (1s) signal signals on peeled PE surface from XPS analysis PE/18-8 laminated films with and without 0.30 MGy HLEBI.

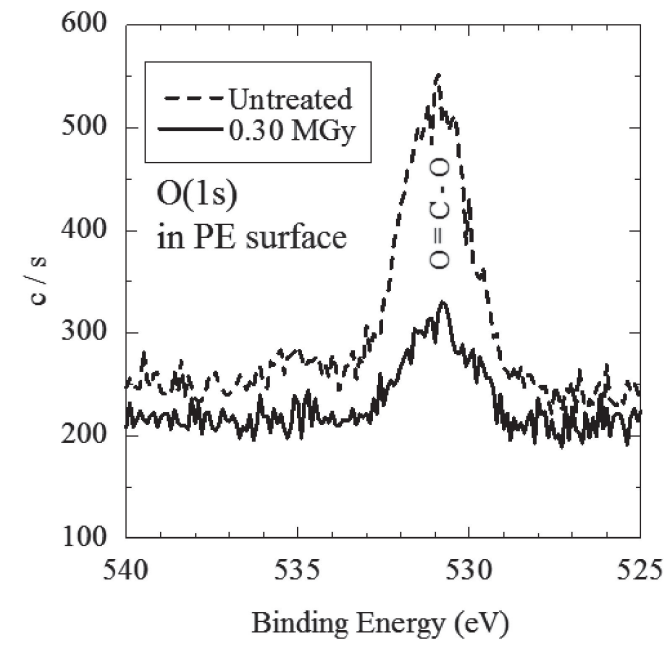

Fig. 8 Oxygen (1s) signals on peeled PE surface from XPS analysis PE/18-8 laminated films with and without 0.30 MGy HLEBI.

ray photoelectron spectrometry (XPS) of carbon (C (1s)) and oxygen $(\mathrm{O}(1 \mathrm{~s}))$ signals of the peeled surface of PE/18-8 laminated sheet with and without $0.30 \mathrm{MGy}$ HLEBI. Results indicate the HLEBI acts to produce adhesion in the PE/18-8 lamination joint where fracture generally occurred near the peeled PE/18-8 interface.

In Fig. 7 the XPS narrow scan of carbon (C (1s)) of the peeled 0.30 MGy sample shows peaks at $\sim 284 \mathrm{eV}$ corresponding with the $\mathrm{C}(1 \mathrm{~s})$ in $\mathrm{C}-\mathrm{C}$ groups. In order to calibrate the results in detail, XPS signals of $\mathrm{C}(1 \mathrm{~s})$ have been obtained for PE with and without HLEBI (Solid and Broken lines in Fig. 7).

The highest intensity of C-C signal for $0.30 \mathrm{MGy}$ sample is gotten. HLEBI increases the carbon ratio of PE to 18-8 stainless.

In order to calibrate the results in detail, XPS signals of $\mathrm{O}$ (1s) in $\mathrm{O}=\mathrm{C}-\mathrm{O}$ have been obtained for $\mathrm{PE} / 18-8$ with and without HLEBI (Solid and Broken lines in Fig. 8). The lowest intensity of $\mathrm{O}(1 \mathrm{~s})$ in $\mathrm{O}=\mathrm{C}-\mathrm{O}$ signals for untreated PE/18-8 is gotten. Since $0.30 \mathrm{MGy}-\mathrm{HLEBI}$ remarkably enhances the intensity, it remarkably enhances the oxygen concentration at PE interface. Since HLEBI activates the 
terminated polymer atoms, oxygen atoms from atmospheric molecules are attracted to surface, and then contaminate the polymers.

It shows that the lamination simply increase the oxygen concentration because of oxygen contamination effects from atmospheric molecules, as shown in Fig. 8. The contamination probably attributes to weak adhesion force of the PE/18-8 lamination untreated, as shown in Figs. 3 and 4.

On the other hand, carefulness must be considered in design since higher dangling bond densities occur from the double-step treatment applying HLEBI doses more than $0.30 \mathrm{MGy}$ acting as crack origins and propagation sites at the laminated interface between PE and 18-8 stainless, degrading the polymers and reducing ${ }^{\circ} F_{\mathrm{p}}$ (see Fig. 4). Therefore, with cautious consideration to dose level, the double-step treatment applying HLEBI prior to hot-press proves a useful method for quick lamination of PE and 18-8 stainless without the use of glue.

\section{Conclusions}

2-layer Polyethylene (PE)/austenitic 18-8 stainless steels (PE/18-8) laminated sheets were prepared by a new adhesion method, a double-step treatment consisting of applying low dose $(\leqq 0.43 \mathrm{MGy})$ of homogeneous low energy electron beam irradiation (HLEBI) prior to hot-press under $5 \mathrm{MPa}$ at $343 \mathrm{~K}$. Although the weak adhesion of 2-layer laminated PE/ 18-8 sheets without our double-step treatment with hot-press after HLEBI had been observed, the strong adhesion of the PE/18-8 was found from the new double-step treatment applying low dose $\leqq 0.43 \mathrm{MGy}$-HLEBI of the 2-layer assembled $\mathrm{PE} / 18-8$ prior to hot-press lamination under $5 \mathrm{MPa}$ at $343 \mathrm{~K}$.

(1) The double-step treatment applying increased HLEBI dose from 0.04 to $0.43 \mathrm{MGy}$ prior to hot-press enhanced the adhesive force of peeling resistance $\left({ }^{\circ} F_{\mathrm{p}}\right)$ at peeling probability $\left(P_{\mathrm{p}}\right)$ of 0.06 and 0.50 .

(2) Based on the 3-parameter Weibull equation, the lowest ${ }^{\circ} F_{\mathrm{p}}$ value at the lowest $P_{\mathrm{p}}$ of zero $\left(F_{\mathrm{s}}\right)$ could be estimated. The double-step treatment applying HLEBI up to $0.30 \mathrm{MGy}$ prior to hot-press apparently improved the $F_{\mathrm{s}}$. The maximum $F_{\mathrm{s}}$ value of the PE/18-8 laminated sheets with hot-press after $0.30 \mathrm{MGy}-\mathrm{HLEBI}$ dose was $0.8 \mathrm{~N} \mathrm{~m}^{-1}$. Consequently, the double-step treatment of applying $0.30 \mathrm{MGy}-\mathrm{HLEBI}$ prior to hot press improved the safety level.

(3) The maximum peeling adhesive force ${ }^{\circ} F_{\mathrm{p}}$ value at low $P_{\mathrm{p}}$ (zero and 0.06 ) of the laminated sheet irradiated at $0.30 \mathrm{MGy}$ were 0.8 and $0.9 \mathrm{~N} \mathrm{~m}^{-1}$, respectively. However, the higher dose of the double-stop treatment applying more than $0.43 \mathrm{MGy}$ HLEBI apparently reduced the ${ }^{\circ} F_{\mathrm{p}}$ at each $P_{\mathrm{p}}$. Therefore, with careful consideration to dose level, the double-step treatment applying HLEBI prior to hot-press proves a useful method for strong and quick lamination of PE and 18-8 stainless with sterilization without the use of glue.

(4) Based on the results of XPS surface analysis for PE/188 laminated sheets after the peeling test, carbon was detected on the peeled PE surface after the double-step treatment. Thus, the adhesion by double-step treatment induced mass transport at the interface of the PE/18-8 layered structure, resulting in strong chemical bonding at interface.

(5) HLEBI up to $0.30 \mathrm{MGy}$ reaching a maximum at 0.8 $\mathrm{Nm}^{-1}$, improving the safety level without radiation damages. When HLEBI cuts the chemical bonds in PE and generates terminated atoms with dangling bonds, they probably induce the chemical bonding. Therefore, increasing adhesion force between the laminated sheets can be explained.

\section{Acknowledgements}

The authors wish to thank Prof. Akira Tonegawa of Tokai University for his useful help. Our sincere gratitude also goes to Eye Electron Beam Co., Ltd. (Gyoda, Saitama, Japan) for their support with this work.

This work was partly supported by the JSPS Core-to-Core Program, A. Advanced Research Networks, "International research core on smart layered materials and structures for energy saving".

\section{REFERENCES}

1) S. Affatato, M. Zavalloni, P. Taddei, M. Di Foggia, C. Fagnano and M. Viceconti: Tribol. Int. 41 (2008) 813-822.

2) A. Minegishi, T. Okada, M. Kanda, M. C. Faudree and Y. Nishi: Mater. Trans. 56 (2015) 1169-1173.

3) K. Oguri, N. Iwataka, A. Tonegawa, Y. Hirose, K. Takayama and Y. Nishi: J. Mater. Res. 16 (2001) 553-557.

4) M. Faudree and Y. Nishi: Mater. Trans. 53 (2012) 1412-1419.

5) A. Oshima, H. Nagai, F. Muto, T. Miura and M. Washio: J. Polym. Sci. Tech. 19 (2006) 123-127.

6) M. Żenkiewicz: Int. J. Adhes. Adhes. 24 (2004) 259-262.

7) Y. Nishi, M. Uyama, H. Kawazu, H. Takei, K. Iwata, H. Kudoh and K. Mitsubayashi: Mater. Trans. 53 (2012) 1657-1664.

8) Y. Nishi, H. Kawazu, H. Takei, K. Iwata, H. Kudoh and K. Mitsubayashi: Mater. Trans. 52 (2011) 1943-1948.

9) C. Kubo, T. Okada, M. Uyama, M. Kanda and Y. Nishi: Mater. Trans 55 (2014) 1742-1749.

10) R. Suenaga, M. Kanda, N. Hironaka and Y. Nishi: J. Japan Inst. Metals 72 (2008) 35-38.

11) T. Shimaru: Technol. Adhes. Seal. 3 (1959) 121-130.

12) M. Seno, K. Kurita, S. Yano and T. Sawaguchi: Basic Polymer Science (Kiso Koubunshikagaku in Japanese), (Kyouritsu Syuppan, Co., Ltd., 2000) pp. 128-129.

13) K. Oguri, N. Iwataka, A. Tonegawa, Y. Hirose, K. Takayama and Y. Nishi: J. Mater. Res. 16 (2001) 553-557.

14) A. Mizutani and Y. Nishi: Mater. Trans. 44 (2003) 1857-1860.

15) K. Sonoda, Y. Kaneda, I. K. Nakazaki, Z. Enomoto and K. Murayama: Proc. the Symposium of Space Sciences and Technology (Utyu kagaku gizyutu renngou kouennkai kouennsyu, JST No. S0277A) 28 (1984) pp. $14-15$

16) K. Oguri, K. Fujita, M. Takahashi, Y. Omori, A. Tonegawa, N. Honda, M. Ochi, K. Takayama and Y. Nishi: J. Mater. Res. 13 (1998) 33683371.

17) K. Oguri, N. Iwatani, H. Izumi, A. Tonegawa, K. Takayama and Y. Nishi: Proc. 2nd Japan-France Seminar on Intelligent Materials and Structures, (University of Louis Pasteur Strasbourg, France) (1998) pp. 142-144.

18) Y. Nishi, A. Mizutani and N. Uchida: J. Thermoplast. Compos. Mater. 17 (2004) 289-302.

19) Y. Nishi, T. Toriyama, K. Oguri, A. Tonegawa and K. Takayama: J. Mater. Res. 16 (2001) 1632-1635.

20) Y. Nishi, A. Mizutani, A. Kimura, T. Toriyama, K. Oguri and A. Tonegawa: J. Mater. Sci. 38 (2003) 89-92.

21) K. Inoue, K. Iwata, T. Morishita, A. Tonegawa, M. Silvia and Y. Nishi: 
Int. J. Appl. Electromag. Mech. 23 (2003) 251-256.

22) Y. Nishi, K. Inoue and M. Salvia: Mater. Trans. 47 (2006) 2846-2851.

23) M. Kanda, K. Yuse, B. Guiffard, L. Lebrun, Y. Nishi and D. Guyomar: Mater. Trans. 53 (2012) 1806-1809.

24) T. Nishida and E. Yasuda: Evaluation of Dynamic Properties of Ceramics (Ceramics no Rikigaku Tokusei Hyouka in Japanese), (Nikkan Kogyou Shimbun Ltd., Tokyo, 1986) pp. 50-51.

25) Y. Nishi, H. Sato, H. Takei and K. Iwata: J. Mater. Res. 24 (2009) 3503-3509.

26) H. Sato, K. Iwata, A. Tonegawa and Y. Nishi: J. Japan Inst. Metals 72 (2008) 526-531

27) H. Takei, M. Salvia, A. Vautrin, A. Tonegawa and Y. Nishi: Mater. Trans. 52 (2011) 734-739.

28) M. Kanda and Y. Nishi: Mater. Trans. 50 (2009) 177-181.
29) K. Iwata and Y. Nishi: Mater. Trans. 51 (2010) 121-127.

30) Y. Nishi, H. Takei, K. Iwata, M. Salvia and A. Vautrin: Mater. Trans. 50 (2009) 2826-2832.

31) K. Iwata and Y. Nishi: Mater. Trans. 49 (2008) 2058-2062.

32) Y. Nishi, H. Kobayashi and M. Salvia: Mater. Trans. 48 (2007) 19241927.

33) N. Tsuchikura, M. C. Faudree and Y. Nishi: Mater. Trans. 54 (2013) 371-379.

34) H. Takei, K. Iwata, M. Salvia, A. Vautrin and Y. Nishi: Mater. Trans. 51 (2010) 2259-2265

35) W. Weibull: Ingeniörs vetenskaps akademien, nr. 153 (Generalstabens litografiska anstalts förlag, Stockholm, 1939) pp. 16-22.

36) Y. P. Yampolskii: Russ. Chem. Rev. 76 (2007) 59-78. 